\title{
How Media Contacts During COVID-19 Influence Political Trust: An Empirical Study of Chinese University Students
}

\begin{abstract}
ZiHan Zhang
Shandong University

"ZiHan Zhang. Email: zihanzhang000818@163.com

ABSTRACT

Focusing on the information dissemination process of COVID-19, this study attempts to investigate the relationship between the frequency of different media use, source trust, and political trust, starting from the media exposure and use of university students. A questionnaire survey was used to collect 371 Chinese university students, with content preference, proximity to the epidemic, cognitive demands, and recognition of media control behaviors as independent variables, and political trust as dependent variables, to explore the link between media exposure and political trust. The results of the study show that for university students the higher the cognitive demands and recognition of media control behaviors, the higher the political trust, and the more frequently traditional media, social media, news clients, and short video platforms are used, the higher the political trust, while the more frequently foreign information channels are used, the lower the political trust. Positive reports and risk information are the main types of information that enhance the political trust of university students. Traditional media such as radio, television, newspapers, and We Media with pertinent official views are the main sources of enhancing political trust, while We Media and marketed media show a significant negative correlation with political trust.
\end{abstract}

Keywords: Political trust, Media contacts, Infodemic, Media malaise, China

\section{INTRODUCTION}

In early 2020, COVID-19 evolved from a regional news story to a global public health event. Media coverage and discussion of COVID-19 has also become a common concern of the population in a country, if not the world, and the information the population received from the media about the outbreak may have an impact on their political trust. Political trust, as one of the most important indicators of government legitimacy, has been of interest to researchers [7] [10] (Easton, 1965; Hetherington, 2008). Media play an important role in constructing attitudes of people toward political trust. Negative coverage of governments in the mass media reduces the political trust of people [28] (Robinson, 1976). Media use causes a decline in social capital and entertainment programs have caused viewers to form more negative opinions about politics, which affects participation or voting behaviors [21] [17] (Miller \& Erbring, 1979; Lichter, 1999). The attempts of the Chinese government to cultivate popular political support through media propaganda have also not been correspondingly effective [38] (Song \& Ma, 2008). The media, as an important institution in shaping public political attitudes, actively constructs cognitive demands of the public by shaping an informed society, enhancing public political interest, improving political cognitive abilities, and ultimately mobilizing them to participate in public affairs, thereby stimulating public trust in politics.

Regarding the effect of media use on political trust, there are still some shortcomings in the existing studies. Firstly, from previous studies, researchers have mainly focused on the relationship between media contacts and political trust of people in everyday situations, lacking research on crises, and unable to explain the special situation of COVID-19. Secondly, because of the differences in political systems, social attitudes, and media environments between the West and China, research findings that focus on Western societies do not apply to the situation in China. For instance, the issue of general elections does not have a similar context in China. At the same time, the Chinese government has adopted a party-controlled media system, and the 
freedom of the press brought about by commercialization, marketization, and industrialization is considered negative freedom that can only be implemented in the non-political sphere [16] (Li, 2004), which differs greatly from the situation of capitalmanaged media in America and Europe. Thirdly, most of the previous studies have explored media use involvement and political involvement from both media and government perspectives [23] [34] (Newton, 1999; $\mathrm{Hu}, 2007$ ), but there lacks description of cognitive demands of the public and its relevance, and there is a need to flesh out how information preferences, active cognition, and relevance of users affect their political trust. At the same time, previous studies have tended to classify media types into official media and We Media, without a more detailed and precise division of each branch [25] [6] (Norris, 2000; Carpini, 2004), which cannot be applied to the changes of media triggered by the new round of technological revolution, and therefore lack a more detailed examination of the influence of media contacts of people on their political trust.

COVID-19 has pushed human society into a major global risk crisis. On the one hand, the existing order of social operation under the epidemic is disrupted. On the other hand, the function of the media is amplified and highlighted. The World Health Organization introduced the concept of infodemic specifically for COVID-19, indicating that too much information can make it difficult for people to find trustworthy sources of information and guidance to rely on, and may even be harmful to the health of people. The disorderly and uncontrolled dissemination of information in society during COVID-19 is a concentrated and dramatic outbreak of discomfort of the population with the new situation. In addition, since university students are a highly educated social group and the future main labor force of a country, their political trust is related to the development of the entire online society and even the country. Therefore, it is of value to study and grasp the real situation of political trust among university students and to properly influence the formation of political trust among university students. This study attempts to answer what is the relationship between media contacts and the political trust of university students during COVID-19.

The researcher found that for university students the higher the frequency of using traditional media, social media, news clients, short video platforms, and We Media with relevant official views, the higher the political trust, while the higher the frequency of using market-oriented media, independent We Media, and foreign information channels, the lower the political trust. Positive reports and risk-based information are the main types of information that enhance the political trust of university students, while help-seeking information undermines the political trust of university students. The higher cognitive demands and recognition of media control behaviors, the higher political trust of university students. In contrast, there is no significant correlation between the proximity to COVID-19 and the political trust of university students.

\section{LITERATURE REVIEW AND RESEARCH HYPOTHESES}

\subsection{Media Contacts}

Uses and gratifications approach initiates a shift in the perspective of mass communication research from a transmitter-based to an audience-based approach [14] (Katz, 1959). Subsequently, the media use of audience was divided into the following basic categories of indicators: the number and types of mass media, the mobility among different types of media, and the perception of and trust in different contents [19] (McQuail, 1997). With the widespread use of the Internet and the deepening of the mediated society brought about by the new technological revolution, the media use measurement indicators developed under the mass communication paradigm may not still be applicable in the Internet era. A new multidimensional research paradigm of media contacts of users was proposed [40] (Yu, 2017), which includes three primary indicators, ranging from basic personal information, media usage habits, and general evaluation, to immediate media exposure behaviors and psychological characteristics in specific situations, from which 13 secondary indicators and 40 tertiary indicators derived. This study expands the measurement dimensions of audience media use about active cognitive demands. In this study, basic personal information, proximity to the epidemic, cognitive demands for information, different types of media, the perceived need for information, frequency of using different types of media, trust in sources, content preference, and recognition of media control are selected, taking into account the special media environment under the epidemic and the media usage habits of the university students.

\subsection{Political Trust}

Political trust is considered the belief or confidence of people, based on rational thinking, practical perceptions, and psychological expectations, that the government or political system will operate to produce results consistent with their expectations [7] [4] [10] (Easton, 1965; Citrin, 1974; Hetherington, 2008). In other words, political trust acts as a political attitude of the population, based on their normative expectations that express a basic orientation of their evaluation of the community, the political system, political performance, institutions and leaders, and socioeconomic development [21] [5] (Miller \& Erbring, 1979; Citrin \& Green,1986). The main explanatory paths of the origins of political trust are divided into institutionalism and 
culturalism. Scholars who support institutionalism believe that political trust is a rational assessment of the trust in and satisfaction with political institutions, government performance, policies, and government actions [20] [24] (Miller \& Borrelli, 1991; Newton, 2001). Proponents of culturalism argue that political trust is derived from inherited ethical habits, the product of moral norms shared by the community, and is rooted in cultural norms, and is the long-standing and deeply rooted beliefs formed through early socialization [8] [30] (Francis, 2001; Mishler \& Rose, 2001). Ethnic culture and values, political culture, social capital, social trust, interpersonal trust, the degree of development of social networks, and individual socialization experiences may all be key factors influencing the trust of in governments [24] (Newton, 2001). Thus, political trust refers to the trust of citizens in the current political system and their acceptance and predictability of social life.

The analyses of Western scholars on political trust in Western countries cannot be directly applied to the particular situation of China, because of the differences between traditional Chinese Confucian culture and modern Western democratic culture. In traditional Confucian culture, the governments and political leaders are the most important symbols of authority in the whole country. For people living in such an environment for a long time since childhood, the sensitivity, admiration, and dependence on authority naturally lead to their trust in the governments and political leaders [18] (Shi, 2001; Lv, 2014). Moreover, ideology is also considered to be an important source of political trust in China. The ruling party of China gains legitimacy by constantly claiming that only under their leadership can economic growth social stability and national independence be achieved [15] [11] (Laliberté \& Lanteigne, 2008; Holbig \& Heike, 2013). The Chinese polity gains authority through patriotic education and performance [29] (Roskin, 2009). Thus, for examining the political trust of Chinese people, it is necessary to take into account the unique cultural background and political system of China. Chinese scholars have operationalized the concept of political trust in the context of China, dividing it into different testing indicators, and integrated each indicator to complete the description of political trust. Firstly, many scholars have measured the core concept of governments, including trust in the political system [36] (Jia \& Meng, 2020), trust in the political community [39] (Xiao \& Wang, 2011), trust in central and local government policies [32] (Dong, 2011), trust in government institutions [33] (Hou, 2013), trust in government prestige [34] $(\mathrm{Hu}, 2007)$, and trust in government competence [37] (Mei, 2009). Secondly, trust in government personnel is also a more important delineator, including trust in political models [39] (Xiao $\&$ Wang, 2011), trust in central and local party officials
[32] (Dong, 2011), and administrative personnel [38] (Song \& Ma, 2008). In addition, public policies are also considered to be important judgment indicators of the responsiveness, implementation ability, and position orientation of governments [37] (Mei, 2009). In summary, this study selected government institutions, government officials, and public policies as three indicators to measure political trust.

\subsection{Media and Political Trust}

Media have become the important sources for people to obtain political information and form political cognition, thus strengthening the influence of media contacts behaviors of people on their political trust. Media Malaise, also known as Mean World Effect Hypothesis [28] [9] (Robinson, 1976; Gerbner et al., 1978), states that the focus of media on reporting negative news causes people to develop negative political attitudes, including political apathy, political alienation, political cynicism, and political distrust [21] [2] [23] (Miller \& Erbring, 1979; Bennett, 1999; Newton, 1999). Because of continuous exposure to and use of the media, the public tends to create a cognitive dislocation of the political environment and form more negative evaluations, leading to a decline in political trust [6] (Carpini, 2004). However, some scholars argue that media exposure helps people develop positive attitudes toward the government system [26] [1] (O'Keefe, 1980; Becker \& Whitney, 2016). Norris (2000) proposed A Virtuous Circle in which there is a positive cycle between the increase in political knowledge, the acquisition of a sense of political participation, and media exposure [25]. Thus, in modern mediated societies with highly developed communication, the access of the public to political information is highly dependent on the media rather than from direct experience, resulting in the media shaping the public's state of political trust.

Rather than a simple positive or negative relationship between media contacts and political trust, it presents a complex relationship depending on the type of media [21] [25] [22] (Miller \& Erbring, 1979; Norris, 2000; Moy \& Pfau, 2000). The content and form of information disseminated by different media types differ, which may lead university students to make different cognitive judgments about the same event and thus take different behavioral decisions. Therefore, frequency of use for different media is a variable to examine. This leads to the following research question.

RQ1. How the media contacts of university students affect their political trust during COVID-19?

The source of trust is an important criterion for people to judge the authenticity of the information. The crisis brought about by COVID-19 has led to an increase in the demand for information authenticity 
among university students, and therefore, the political trust of university students is more likely to be affected to different degrees during COVID-19 when they are confronted with information from different sources than in normal times. This leads to the research question.

RQ2. How different trust levels of sources affect the political trust of university students during COVID-19.

The preference of the audience to pay attention to different contents of the media is also a factor in considering the political trust of the audience. When coverage focuses on crime, conflict, political incompetence and corruption, sex and scandal, and other negative events [16] [23] (Lichter, 1999; Newton, 1999), it may lead to the development of political cynicism and a decrease in the trust in governments [13] [3] (Kaid \& Johnston, 1991; Cappella \& Jamieson, 1998). During COVID-19, university students who are overly concerned about negative information or rumors related to the epidemic are prone to a state of stress that affects their health management decisions and personal protective behaviors, and further exacerbates anxiety. These negative emotions may lead to distrust in society and governments. In addition, the structure of the demand of university students for epidemic information is not stable but constantly shifts with the development of the epidemic, public opinion, and hot events. In this case, the media-influenced political trust of university students during COVID-19 is not a lasting trust, but a matching trust with dynamic change characteristics [36] (Jia \& Meng, 2020). As a result, the tendency of university students to choose the content of media messages may have an impact on their political trust. Therefore, the following hypothesis is proposed.

H1. Preferences of university students for attention to different information contents affect their political trust during COVID-19.

H1a. Information content preferences for helpseeking information will negatively affect political trust.

H1b. Information content preference for positive reports will positively influence political trust.

H1c. Information content preference for risk information will positively influence political trust.

Proximity, one of the basic elements of news value, refers to the relevance of news to the audience in terms of geography, gender, thoughts, and emotions [12] (Jenkins \& Nielsen, 2020). The more closely the people are associated with the news content, the more they will appear to care. Although COVID-19 is of concern to the Chinese as a major public crisis event, the epidemic still mainly revolves around the Hubei region, and the degree of negative impacts that the people are subjected to from the epidemic disperse in a stepwise manner, including threats to life safety, threats to property safety, and restrictions on personal freedom. This may lead to different attitudes of university students in different regions towards different government policies and behaviors, i.e., the higher the correlation with the Hubei region, the greater the negative impact of the epidemic on university students, and thus the more they may rely on the ability of governments to maintain their survival. Hence, the following hypothesis is developed.

$\mathrm{H} 2$. The higher the proximity of university students to Hubei (the core region where the epidemic is relatively severe and concentrated) during COVID-19, the higher the political trust.

In a public health emergency, access to news and information is a necessary way for the public to stay informed, dispel fears, and actively protect themselves in the face of a disaster. COVID-19 is a serious and complex disaster that is difficult for ordinary people to cope with based on common sense and experience. In the face of great uncertainty during the epidemic, individual-level perceptions of epidemic risk are often associated with media use [27] (Oh, 2015), individuals often need the media to obtain disease information, reduce uncertainty in their perception of the environment, and form subjective perceptions and behavioral directions about the epidemic. Thus, with the consequent increase in cognitive demands, the more truthful and comprehensive the information available to university students will be, reducing the impact of rumors against the governments on them, which may positively influence their political trust. Therefore, the following hypothesis is proposed.

H3. The higher the cognitive demands for information about COVID-19 among university students during COVID-19, the higher the political trust.

The recognition of media control practices of governments also affects the level of political trust of university students. The media of China is strictly controlled, and its news coverage is a production of the information under the control of layers of political power. Under the special circumstances of COVID-19, to prevent panic and stabilize the minds of people, the news media will set the appropriate communication agenda and communication content, and adopt officially directed emergency propaganda strategies for public opinion guidance and public opinion management. However, when the public is faced with strictly controlled media, they may become dissatisfied with media control behaviors of governments and thus develop distrust in governments. As a result, university students who are more accepting of media control behaviors of governments may be more willing to receive media information in the face of media control behaviors of governments thus increasing their political trust. Therefore, we suggest the following hypothesis. 
H4. During COVID-19, the more university students approve of media control behaviors, the higher their political trust

\section{METHODOLOGY}

\subsection{Data collection}

A total of 371 questionnaires contained 18 questions were returned in this survey, and the number of valid questionnaires was 367 by testing for extreme and missing values. Among them, the sample size of males was 166 and the sample size of females was 201. On the level of educational background, the sample sizes of specialist, bachelor, master, and doctor were 18, 210, 112 , and 27 respectively. On the level of political outlook, the sample sizes of masses, members of the Communist Youth League, activists of the Communist Party of China, and members of the Communist Party of China (including reserve members) were 37, 207, 34, and 89 respectively.

\subsection{Measurement}

\subsubsection{Independent variables}

Frequency of media use. Refer to The 44th China Statistical Report on Internet Development of CNNIC [31] and 2017 China Netizen Consumption Upgrade and Content Upgrade Insights Report of iResearch [35], traditional media (radio, television, newspapers, etc) is merged into one category, and Internet media is divided into news clients (CCTV News, Toutiao, etc.), social media (WeChat, Weibo, Douban, etc.), short video platforms, and other categories juxtaposed with traditional media, forming a total of 13 media types.

Trust in the sources. Combining the typical characteristics of information publishers, the sources of information are divided into mainstream media (People's Daily, Xinhua News Agency, etc.), marketoriented media (Caixin Weekly, Sanlian Lifeweek Magazine, etc.), and We Media with views close to the official (Today Comments by Xiaoping, Observation by Xijin $\mathrm{Hu}$, etc.), independent We Media (Yoyo Luming, Septuple Space, etc.), overseas media (Facebook, Twitter, etc.), individuals (relations from relatives and friends or other individuals on social media, etc.).

Proximity to the epidemic. It mainly examines the relationship and distance between the survey respondents and COVID-19, including whether they stay, work or go to school in Hubei in terms of geographic distance, whether there are relatives or friends in Hubei at the relationship level, and whether they or their relatives and friends have been infected with new coronary pneumonia, measured by dichotomy.
Cognitive demands. Such indicators reflect the connection between the survey respondents and the epidemic in the cognitive dimension, including the initiative to obtain epidemic information, the acceptance of epidemic information, and the degree of critical thinking. For example, I am more concerned about the information on the COVID-19, I will read the views I disagree with, I will contact or read the views of unfamiliar sources of information, and I will change my original views through further thinking and verification. Using the 5-level Likert scale to investigate whether there is a correlation between the willingness of respondents to acquire and think about the epidemic information and political trust, Cronbach's $\alpha=0.678$.

Content preference. According to the characteristics of information content presented during the epidemic, the content is divided into 9 categories: risk information, response information, help-seeking information, and positive energy reports, and survey preference of respondents for information content. The three types of independent variables, media usage frequency, source trust, and content preference are all measured by the 5level Likert scale, using predictive multiple regression analysis. Among the independent variables, since the three factors including media use frequency, content preference, and source trust are measured through categorical variables, no reliability analysis is performed.

Recognition of media control behaviors. Combining with representative media events during the epidemic, we see that the control of media content may trigger a large-scale backlash in online public opinion. Through investigating attitudes to common online media control behaviors, we examine the relationship between media control and political trust, including the official account only screens out comments praising the government, deleting negative comments on Weibo about the epidemic, some articles are set to prohibit comments or prohibit sharing, etc. Measured on a five-point Likert scale, from 1 to 5 representing strongly disagree to fully agree, Cronbach's $\alpha=0.747$. Performing interpretation regression analysis.

The control variables include gender, age, education level, professional orientation, and political outlook.

\subsubsection{Dependent variable}

Since there is no previous scale related to Chinese political trust during a public health crisis, this study constructs and develops a related scale. Based on the literature review of relevant research above, this study divides the dependent variable political trust into three dimensions: trust in government agencies, trust in government officials, and trust in public policies, using a 5-level Likert measurement to measure it in the presurvey. 
A total of 40 items were compiled in the early stage, including 13 inverse questions. The designed questions are all around COVID-19, reflecting media events and public opinion that have received widespread attention during the epidemic. For example, the trust in the government is measured by asking respondents whether they agree with one province, one city (Jiangsu Province's support for Huangshi) reflects the superiority of the political system of China and whether the handling by the action of the Chinese government is more reasonable and effective than the government of other countries. The measurement of trust in government officials mainly includes national leaders going to Wuhan during COVID-19 made me confident in overcoming the epidemic, government officials exposed more formalism during COVID-19, and Wuhan change leadership during COVID-19 is timely. The measures of trust in public policies, including management policies of the government for immigrants are in place during the epidemic, closing counties, towns, and villages are unnecessary epidemic prevention and control measures, and policies of the government on overseas Chinese students (For example, it is reasonable to distribute health packs). The 5-level Likert scale is used to measure the question, from 1 to 5 representing strongly disagree to fully agree. Cronbach's alpha of these three public factors is $0.930,0.899$, and 0.824 , respectively. Cronbach's alpha of the dependent variable total table is 0.923 .

Table 1. Some items in the pre-survey scale

Political trust classification The degree of agreement with the following statements is (1=strongly disagree,
2=partially disagree, $3=$ hold a neutral position, 4=partially agree, 5=completely agree)

The handling of the central government of the epidemic is effective

\begin{tabular}{|c|c|}
\hline $\begin{array}{l}\text { Trust in } \\
\text { agencies }\end{array}$ & $\begin{array}{l}\text { Confidence in the ability of the central government to control the development of the } \\
\text { epidemic } \\
\text { Confidence in the ability of local governments to control the development of the } \\
\text { epidemic }\end{array}$ \\
\hline $\begin{array}{l}\text { Trust } \\
\text { officials }\end{array}$ & $\begin{array}{l}\text { Grassroots protection personnel have made important contributions to epidemic } \\
\text { control } \\
\text { The violent prevention and control incidents of epidemic prevention personnel that } \\
\text { occurred during the epidemic are barbaric acts }\end{array}$ \\
\hline & $\begin{array}{l}\text { It is acceptable for the police to use some coercive measures during the control of the } \\
\text { epidemic } \\
\text { Measures that the government can guarantee the stable supply of protective materials } \\
\text { such as masks and disinfectants }\end{array}$ \\
\hline Trust in public policy & $\begin{array}{l}\text { The management policies of the government for overseas import managers are in } \\
\text { place } \\
\text { The government actively promotes the resumption of work and production will help } \\
\text { promote social stability }\end{array}$ \\
\hline
\end{tabular}

\section{FINDINGS}

The variables in this study mainly include moderating variables (gender, educational background, political outlook), independent variables (frequency of media use, content preference, trust in the sources, proximity to the epidemic, cognitive demands, and recognition of media control behaviors), dependent variables (political trust). The statistical analysis methods used are different due to the different types of variables.

This study has 6 independent variables. These 6 independent variables cannot be used for multiple regression analysis at the same time because of the different types of variables. In particular, frequency of media use, content preference, and trust in the source are categorized variables. Predictive regression analysis adopts multiple stepwise regression algorithm. Independent variables proximity to the epidemic, cognitive demands, and recognition of media control behaviors belong to the Likert scale, so simple linear regression and explanatory regression analysis are performed, and the method of forced entry variable is used. Through the above two methods, the following 3 forms can be obtained: 
Table 2. Predictive regression analysis results of independent variables frequency of media use, content preference and trust in the sources

\begin{tabular}{|c|c|c|c|c|c|c|c|}
\hline $\begin{array}{l}\text { Input } \\
\text { variable } \\
\text { order }\end{array}$ & $\begin{array}{l}\text { Multiple } \\
\text { Correlation } \\
\text { coefficient }\end{array}$ & $\begin{array}{l}\text { Coefficient } \\
\text { Of } \\
\text { Determination } \\
\text { R2 }\end{array}$ & $\begin{array}{l}\text { Increase } \\
(\triangle R 2)\end{array}$ & $\begin{array}{l}\mathrm{F} \\
\text { value }\end{array}$ & $\begin{array}{l}\text { Net } \\
\mathrm{F} \\
\text { Value } \\
(\triangle \mathrm{F}) \\
\end{array}$ & $B$ & $\begin{array}{l}\text { Beat } \\
\text { ( } \beta)\end{array}$ \\
\hline Intercept & & & & & & 41.466 & \\
\hline 1.News Client & 0.299 & 0.090 & 0.087 & 35.906 & 35.906 & 1.237 & 0.165 \\
\hline 2.Short video platform & 0.358 & 0.128 & 0.124 & 26.828 & 16.251 & 1.094 & 0.173 \\
\hline 3.Traditional media & 0.391 & 0.153 & 0.146 & 21.791 & 10.340 & 1.551 & 0.212 \\
\hline 4.Foreign information channels & 0.413 & 0.171 & 0.162 & 18.645 & 7.954 & -1.045 & $-\overline{0} 147$ \\
\hline $\begin{array}{l}\text { 5.Social media } \\
\text { Intercept }\end{array}$ & 0.433 & 0.187 & 0.176 & 16.634 & 7.296 & $\begin{array}{l}1.318 \\
35.062\end{array}$ & 0.132 \\
\hline 1.Positive Report & 0.530 & 0.281 & 0.279 & 142.306 & 142.306 & 5.660 & 0.582 \\
\hline 2.Help-seeking information & 0.551 & 0.304 & 0.300 & 79.488 & 12.274 & -1.866 & $\overline{-} .215$ \\
\hline 3.Risk information & 0.564 & 0.318 & 0.313 & 56.465 & 7.555 & 1.590 & 0.135 \\
\hline $\begin{array}{l}\text { Intercept } \\
\text { 1.Mainstream media } \\
\text { Table } 2 \text { (continued) }\end{array}$ & 0.389 & 0.151 & 0.149 & 65.010 & 65.010 & $\begin{array}{l}44.994 \\
3.753\end{array}$ & 0.471 \\
\hline $\begin{array}{l}\text { Input } \\
\text { variable } \\
\text { order }\end{array}$ & $\begin{array}{l}\text { Multiple } \\
\text { Correlation } \\
\text { coefficient }\end{array}$ & $\begin{array}{l}\text { Coefficient } \\
\text { Of } \\
\text { Determination } \\
\text { R2 }\end{array}$ & $\begin{array}{l}\text { Increase } \\
(\triangle R 2)\end{array}$ & $\begin{array}{l}\mathrm{F} \\
\text { value }\end{array}$ & $\begin{array}{l}\text { Net } \\
\mathrm{F} \\
\text { Value } \\
(\Delta \mathrm{F})\end{array}$ & B & $\begin{array}{l}\text { Beat } \\
\text { (B) }\end{array}$ \\
\hline 2.Market-oriented media & 0.423 & 0.179 & 0.175 & 39.701 & 12.367 & -1.336 & 0.413 \\
\hline $\begin{array}{l}\text { 3.Official We Media with } \\
\text { appropriate views }\end{array}$ & 0.448 & 0.200 & 0.194 & 30.321 & 9.671 & 1.809 & 0.429 \\
\hline 4.Independent from the media & 0.472 & 0.223 & 0.214 & 25.942 & 10.438 & -1.416 & 0.438 \\
\hline
\end{tabular}

Table 2 shows the predictive regression analysis results of the independent variables frequency of media use, content preference, and trust in the sources. In the original scale, the media use frequency included 13 media types. After the stepwise multiple regression method was tested, 5 media types that were obviously related to political trust were retained, with a total explanation level of $18.7 \%$. Among them, the use frequency of foreign information channels is significantly negatively correlated with the dependent variable political trust, while the contacts and use frequency of the remaining four media types is significantly positively correlated with the dependent variable. The relative strengths are ranked as traditional media, Social media, news client, short video platform.

On the scale of content preference, there were originally 9 themes. After stepwise multiple regression analysis, 3 content themes that are significantly related to the dependent variable are retained, with a total explanation level of $31.3 \%$. Among them, the greater the preference of users for help-seeking information, the more significant the negative correlation between political trust, while positive reports and risk information are positively correlated with political trust, and the correlation between positive energy reports and political trust is higher than the correlation between risk information and political trust.

On the scale of trust in the sources, there originally included 6 types of information sources. After stepwise multiple regression analysis, 4 types of information sources were retained, with a total explanation level of 22.3\%. Among them, market-oriented media, independent We Media, and political trust are significantly negatively correlated, while mainstream media and official We Media with appropriate views show a significant positive correlation with political trust. Mainstream media is the most powerful form of political trust. Types of information sources and independent We Media have the most significant negative effect on political trust. 
Table 3. Regression analysis results of proximity to the epidemic, cognitive demands, and recognition of media control behaviors 1

\begin{tabular}{|c|c|c|c|c|c|c|c|c|c|c|}
\hline \multirow[b]{2}{*}{ Model } & \multirow[b]{2}{*}{$\mathrm{R}$} & \multirow[b]{2}{*}{$\mathrm{R} 2$} & \multicolumn{5}{|c|}{ Model summary } & \multirow[b]{2}{*}{$\begin{array}{l}\text { Degree } \\
\text { of } \\
\text { freedom } \\
2\end{array}$} & \multirow[b]{2}{*}{$\begin{array}{l}\text { Signi- } \\
\text { fican-ce }\end{array}$} & \multirow[b]{2}{*}{$\begin{array}{l}\text { Durbin- } \\
\text { Watson }\end{array}$} \\
\hline & & & $\begin{array}{l}\text { Adjusted } \\
\text { R2 }\end{array}$ & $\begin{array}{l}\text { Standard } \\
\text { esti-mation } \\
\text { error }\end{array}$ & $\begin{array}{l}\text { The } \\
\text { amount } \\
\text { of } \\
\text { change } \\
\text { in R2 }\end{array}$ & $\begin{array}{l}\text { The } \\
\text { amount } \\
\text { of } \\
\text { change } \\
\text { in F }\end{array}$ & $\begin{array}{l}\text { Degree of } \\
\text { freedom } \\
1\end{array}$ & & & \\
\hline 1 & 0.068 & 0.005 & 0.002 & 9.76833 & 0.05 & 1.683 & 1 & 365 & 0.2 & 1.916 \\
\hline 2 & 0.329 & 0.108 & 0.106 & 9.24585 & 0.108 & 44.296 & 1 & 365 & 0 & 1.922 \\
\hline 3 & 0.253 & 0.064 & 0.061 & 9.47251 & 0.064 & 24.943 & 1 & 365 & 0 & 1.98 \\
\hline \multicolumn{11}{|c|}{$\begin{array}{l}\text { Model 1. Predictor variable: (constant), proximity the epidemic; } \\
\text { Model 2. Predictors: (constant), cognitive demands; } \\
\text { Model 3. Predictor variable: (constant), recognition of media control behaviors; } \\
\text { Dependent variable: political trust }\end{array}$} \\
\hline
\end{tabular}

Table 4. Regression analysis results of proximity to the epidemic, cognitive demands, and recognition of media control behaviors 2

\begin{tabular}{|c|c|c|c|c|c|c|c|}
\hline \multirow{3}{*}{ Model } & \multicolumn{5}{|c|}{ Coefficient } & & \\
\hline & \multicolumn{2}{|c|}{$\begin{array}{l}\text { Unstandardized } \\
\text { coefficient }\end{array}$} & \multirow[t]{2}{*}{$\begin{array}{l}\text { Standardization } \\
\text { factor }\end{array}$} & \multirow[t]{2}{*}{$\mathrm{t}$} & \multirow[t]{2}{*}{ Significance } & \multicolumn{2}{|c|}{ Collinearity statistics } \\
\hline & B & $\begin{array}{l}\text { Standard } \\
\text { error }\end{array}$ & & & & Tolerance & VIF \\
\hline 1 (constant) & 52.095 & 4.034 & & 12.914 & 0.000 & & \\
\hline $\begin{array}{l}\text { Proximity to the } \\
\text { epidemic }\end{array}$ & 0.697 & 0.537 & 0.068 & 1.297 & 0.195 & 1.000 & 1.000 \\
\hline 2 (constant) & 39.004 & 2.789 & & 13.985 & 0.000 & & 1.000 \\
\hline $\begin{array}{l}\text { Cognitive } \\
\text { demands }\end{array}$ & 1.134 & 0.170 & 0.329 & 6.656 & 0.000 & 1.000 & 1.000 \\
\hline 3 (constant) & 50.737 & 1.401 & & 36.205 & 0.000 & & \\
\hline $\begin{array}{l}\text { Recognition of } \\
\text { media control } \\
\text { behaviors }\end{array}$ & 0.768 & 0.154 & 0.253 & 4.994 & 0.000 & 1.000 & 1.000 \\
\hline $\begin{array}{l}\text { Model 1. Predictor } \\
\text { Model 2. Predictors } \\
\text { Model 3. Predictor } \\
\text { Dependent variable }\end{array}$ & $\begin{array}{l}\text { variable: } \\
: \text { (consta } \\
\text { variable: } \\
\text { : political }\end{array}$ & $\begin{array}{l}\text { onstant), pr } \\
\text { ), cognitive } \\
\text { onstant), re } \\
\text { rust }\end{array}$ & $\begin{array}{l}\text { imity to the epide } \\
\text { mands; } \\
\text { gnition of media }\end{array}$ & ic; & rs; & & \\
\hline
\end{tabular}

Table 3 shows the results of the explanatory regression analysis of the independent variables proximity to the epidemic, cognitive demands, and recognition of media control behaviors. The results showed that there was no significant correlation between proximity to the epidemic and political trust $(\mathrm{p}=0.195>0.05)$, while cognitive demand and recognition of media control behaviors both showed a significant correlation with political trust $(p=0.000<0.05)$. At this time, further regression analysis can be performed to obtain the data in Table 4. Since there is no significant correlation between proximity to the epidemic and political trust, data such as regression coefficients are not statistically significant. Cognitive demands and recognition of media control behaviors are all positively correlated with political trust, and the standardization coefficients are 0.329 and 0.253 , respectively.
According to the above data analysis, gender and political outlook have no significant moderating effects on political trust. In the educational background, the moderating effects of undergraduates and masters are significantly different. Among the independent variables, there is no significant correlation between proximity to the epidemic and the dependent variable political trust. Both cognitive demands and recognition of media control behaviors are positively correlated with political trust. The data results of this study support H1, H3, H4 but oppose $\mathrm{H} 2$.

\section{CONCLUSION AND DISCUSSION}

This study found a high correlation between media contacts of university students and their political trust during COVID-19, providing a new perspective on the study of media influence on the political trust of 
university students. First, the frequency of use of different media types and trust in sources have different effects on the political trust of university students. The strongest positive correlation with political trust is in traditional media, followed by social media, news clients, short video platforms, and We Media whose views are close to the official ones. In contrast, marketoriented media, independent We Media, and foreign information channels are negatively related to political trust among university students. Such a result is also a new perception of Media Malaise [28] (Robinson, 1976). While most of the scholarship on the impact of media on political trust has focused on negative effects, the impact of media on political trust during COVID-19 has been mostly positive. For university students, home isolation led to an increase in the use of television and newspapers, and their reception of messages from these types of media increased as a result. At the same time, the use of social media, news clients, short video platforms, and other Internet media is more widespread and more involved for university students than for other age groups. Secondly, the preference of university students for attention to different information contents also has a significant correlation on their political trust. Help-seeking information has a negative impact on political trust, while the greatest positive impact on political trust is positive reports, followed by risk information. A large amount of help-seeking information is released and disseminated by individual users through social media platforms, which is highly subjective and specific, and sometimes even contains false information, which may lead to the misunderstanding of the work and ability of the government. At the same time, timely positive reports and risky information enable university students to learn about the epidemic and the good results of the epidemic prevention work as soon as possible, which can avoid the psychological anxiety caused by the information gap and improve the trust of university students in work of the government. Furthermore, it was found that the recognition of media control behaviors during the epidemic has a direct negative impact on the political trust of the university students. To ensure truthfulness and reliability and reduce the spread of rumors during the epidemic, the Chinese government tightened its control over the media and regulated the scope of media that could participate in the collection of information about the epidemic at the level of ownership and level through administrative orders, resulting in a greater proportion of official information available to the public in the media, which might lead to their discomfort, especially for university students who are critical and have strong information-gathering skills. In addition, in terms of cognitive demands, the study found that the media is a good source of information. In addition, in terms of cognitive demands, the study found a significant positive relationship between cognitive demands of university students for information about
COVID-19 and their political trust, i.e., the more they are deeply involved in obtaining information, integrating different opinions, and willing to further think about and verify the truth of the information, the more they can deepen their trust in politics. This result confirms the aforementioned A Virtuous Circle between media and political trust [25] (Norris, 2000). Finally, there was no significant correlation between the proximity to the epidemic and the political trust of university students. I believe that this result may be due to my problematic definition of the proximity of COVID-19, a major crisis event. Wuhan and the entire Hubei region did serve as the focus of social attention during the initial outbreak and the spreading phase of the epidemic, but when the epidemic swept across the globe and the entire human race had become a de facto community of fate in the face of the virus, the proximity to the Hubei region was not reflected by the proximity of the crisis in substance.

The results of the study shed new light on the efforts of the government to enhance the political trust of university students through the media during COVID-19. The governments can adjust the content of epidemic information and dissemination media according to the information needs of university students, such as strengthening the linkage between mainstream media and We Media platforms that are relevant to official views, so that official information can gain more attention and recognition from university students. At the same time, unofficial media can introduce authoritative sources in the production of epidemic information, such as operational cooperation with government organizations and medical institutions, and at the same time use technology to accurately combat rumors and adjust algorithmic mechanisms to improve the efficiency of authoritative information dissemination. Second, in the face of public crisis events like COVID19, the right of the public to know needs to be guaranteed. However, in the context of infodemic, the right to know is not the same as a large amount of information that is hard to distinguish from the truth. The Chinese government needs to regulate the information disseminated by the media to a certain extent, but the extent to which the media control of the government is reasonable and legitimate, and how to define the boundaries of its power, are questions that the government needs to solve.

This paper is a study of Chinese university students, but the descriptive results are not necessarily of generalizable value because the questionnaire was distributed only on the Internet and the respondents were not evenly distributed by geography due to the limitation of technical means. However, since this is a real and widely sourced sample with a large volume, the relationship between the variables can be tested, so the main findings of this paper, especially the new perception of Media Malaise based on the special 
context of COVID-19, are of enlightening value and theoretical significance and deserve further attention and verification in subsequent studies. It deserves further attention and verification. In addition, the rapid development of the epidemic from a regional problem to a global catastrophe has led to different real-time situations in the initial design of the study, in the collection of data, and in the drawing of conclusions, so the research questions, data, and conclusions may lag. However, the findings reached in this paper are also based on the real situation at a given time. Future research can explore the impact of media exposure on political trust in depth based on the ideas of this study in conjunction with the real-time situation to compensate for the time lag.

\section{REFERENCES}

[1] Becker, L. B. , \& Whitney, D. C. . (2016). The effects of media dependencies on audience assessment of government. Communication Research, 7(1), 95-120.

[2] Bennett, S. E., Rhine, S. L., Flickinger, R. S., \& Bennett, LLM. . (1999). Video Malaise: RevisitedPublic Trust in the Media and Government. The International Journal of Press/Politics, 4(4): 8-23.

[3] Cappella, J. N., \& Jamieson, K. H. (1998). Spiral of cynicism: the press and the public good. Oxford University Press.

[4] Citrin, J. (1974). Comment: the political relevance of trust in government. American Political Science Review, 68(3), 973-988.

[5] Citrin, J. , \& Donald, P. G. . (1986). Presidential Leadership and the Resurgence of Trust in Government. British Journal of Political Science 16(October).

[6] Carpini, M. (2004). Mediating Democratic Engagement: The Impact of Communications on Citizens' Involvement in Political and Civil Life.

[7] Easton, D. (1965). A Systems Analysis of Political Life. New York: Wiley.

[8] Francis, F. (1996). Trust: The Social Virtues and The Creation of Prosperity. Free Press.

[9] Gerbner, G., Gross, L. , Jackson-Beeck, M. , Jeffries-Fox, S. , \& Signorielli, N. . (2010). Cultural indicators: violence profile no. 9. Journal of Communication, 28(3), 176-207.

[10] Hetherington, Marc, J., Rudolph, Thomas, \& J. (2008). Priming, performance, and the dynamics of political trust. Journal of Politics.
[11] Holbig, \& Heike. (2013). Ideology after the end of ideology. china and the quest for autocratic legitimation. Democratization, 20(1), 61-81.

[12] Jenkins, J., \& Nielsen, R. K. (2020).Proximity, Public Service, and Popularity: A Comparative Study of How Local Journalists View Quality News. Journalism Studies(2), doi:10.1080/1461670X.2019.1636704.

[13] Kaid, L. L., \& Johnston, A. (2006). Negative versus positive television advertising in u.s. presidential campaigns, 1960-1988. Journal of Communication, 41(3), 53-064.

[14] Katz, E. (1959). Mass communications research and the study of popular culture: an editorial note on a possible future for this journal. Studies in Public Communication. pp. $1-6$.

[15] Laliberté, A., \& Lanteigne, M. (2008). The chinese party - state in the 21 st century: adaptation and the reinvention of legitimacy. London and New York: Routledge.

[16] Li, J. Q. (2004). Beyond western hegemony: media and chinese modernity. Hong Kong: Oxford University Press, 80-84.

[17] Lichter, S. R., Lichter, L. S., \& Amundson, D. (1999). Images of government in TV entertainment. Washington, DC: Center for Media and Public Affairs.

[18] Lv, X. B. (2014). Social policy and regime legitimacy: the effects of education reform in China. American Political Science Review. 2: 423 37.

[19] McQuail, D. (1997). Audience Analysis. SAGE Publications, Inc.

[20] Miller, Arthur, H., Borrelli, Stephen, \& A. (1991). Confidence in government during the 1980s. American Politics Quarterly.

[21] Miller, A. H., \& Erbring, G. L. (1979). Type-set politics: impact of newspapers on public confidence. American Political Science Review, $73(1), 67-84$.

[22] Moy, P., \& Pfau, M. (2000). With malice toward all? : the media and public confidence in democratic institutions. Journalism \& Mass Communication Quarterly, 77(4), 933-934.

[23] Newton, K. (1999). Mass media effects: mobilization or media malaise? British Journal of Political Science, 29(4), 577-599.

[24] Newton, K. (2001). Trust, social capital, civil society, and democracy. International Political Science Review, vol. 22, No. 2: 201-214. 
[25] Norris, P. (2000). A Virtuous Circle. Cambridge, UK: Cambridge University Press.

[26] O'Keefe, \& Garrett, J. (1980). Political malaise and reliance on media. Journalism Quarterly 57: 122 128.

[27] Oh, S. H., Paek, H. J., \& Hove, T. (2015). Cognitive and emotional dimensions of perceived risk characteristics, genre-specific media effects, and risk perceptions: the case of h1n1 influenza in south korea. Asian Journal of Communication, 25(1), 14-32.

[28] Robinson, M. J. (1976). Public affairs television and the growth of political malaise: the case of "the selling of the pentagon". American Political Science Review, 70(2), 409-432.

[29] Roskin, M. G. (2009). Countries and concepts: politics, geography, culture. New York: Pearson/Longman.

[30] Mishler, W., \& Rose, R. (2001). What are the origins of political trust? testing institutional and cultural theories in post-communist societies. Comparative Political Studies, 34(1), 30-62.

[31] CNNIC. 2019. The 44th China Statistical Report on Internet Development. http://www.cac.gov.cn/pdf/20190829/44.pdf

[32] Dong, Y. (2011). The Media Contacts and Political Trust of The Grassroots People: Based on the Research of Migrant Workers. Fudan University.

[33] Hou M. T. (2013). The formation mechanism of political trust of the urban residents. Nanjing University.

[34] Hu R. (2007). The petition of farmers and erosion of political trust in government. Sociological Studies, 03: 39-55+243.

[35] iResearch. 2017. 2017 China Netizen Consumption Upgrade and Content Upgrade Insights Report. http://report.iresearch.cn/report_pdf.aspx?id=3008

[36] Jia Z. M., \& Meng T. G. (2020). The information axis: media use, information needs and media trust during the new coronavirus outbreak. EGovernment, 05: 14-27.

[37] Mei, Z. R. (2009). The political trust level measurement indicators and current situation in china. Social Sciences in Yunnan, 2:5-9.

[38] Song, S. P., \& Ma, B. B. (2008). On the structure of political trust. Administration and Law, 8: 2527.

[39] Xiao, T. B., \& Wang, X. (2011). How to gain or lose the heart of peoplet? an analysis of factors affecting the political trust of peasants: a survey of 60 villages in five provinces (cities) (1999-2008). China Rural Survey, 6: 75-82.

[40] Yu, G. M., He, Q. C., \& Wu, W. X. (2017). The innovation of communication research paradigm: studying media exposure and media use. Journalism Research, 01: 85-93, 150. 